\title{
ARTHROPLASTY OF THE HIP
}

\author{
R. A. Denham, Pyrford and Chertsey, England \\ and \\ W. Alexander Law, London, England
}

During the last four years a review of 211 hip arthroplasties performed by various surgeons in different parts of the country has been compiled by one of us (R. A. D.). The aim of the investigation was to discover if there were any factors that were frequently associated with success or failure of this operation. This paper summarises some of the results of this work; it includes some technical details of the operative approach that has so far achieved the highest percentage of success.

\section{MATERIAL AND GENERAL INFORMATION}

A number of factors in each patient's pre-operative, operative and post-operative phases have been tabulated for analysis. The probable causes for success and failure have been found by comparing these factors in the excellent, good and bad results.

None of the 211 cases included in the statistical series was observed for less than twelve months after operation. The average post-operative period was fifty-nine months in the case of the Smith-Petersen moulds, and twenty-five months in the case of the Judet prostheses. There was a 94.7 per cent attendance for the follow-up examination. Cases were consecutive; there was no " selection" of cases. All percentages recorded in tables and illustrations are percentages of 211 cases of hip arthroplasty.

A new method was used to classify results. It is submitted that this classification gives a more accurate assessment of results than do other methods in current use. In the analysis which follows, groups of excellent (E), good (G) and bad (B) results are compared (Table I).

TABLE I

Criteria Used in Assessing and Classifying the Results of Arthroplasty

\begin{tabular}{|c|c|c|c|c|c|c|c|c|}
\hline & \multirow{2}{*}{\multicolumn{2}{|c|}{ Result }} & \multicolumn{6}{|c|}{ Factors considered in assessment of result } \\
\hline & & & ' & & Pain & Opinion & Movement & Function \\
\hline \multirow{3}{*}{$\begin{array}{l}2 \\
3\end{array}$} & Excelle & $t=E$ & & & "None" & Satisfied with result & Good & Good \\
\hline & Good & $=\mathrm{G}$ & “ & "A little," ' & "Very occasional" & Satisfied with result & Good & Good \\
\hline & Bad & $=\mathbf{B}$ & & "A 1 & lot of pain" & Dissatisfied with result & Good or bad & Good or bad \\
\hline & & & & 4 Interm & ediate groups - Cor & nbinations of these fou & factors & \\
\hline
\end{tabular}

Analysis is a tricky weapon with which to attack a human problem, for the variable factors are many, and the patients relatively few; however, we do hope to show that there are only four factors which greatly influence the result of an arthroplasty.

Selection of cases for operation-Patients should be selected for operation mainly on account of pain. If they cannot sit, sleep or walk in comfort because of pain, surgical treatment should certainly be considered. If the patient is young, has a normal hip on the opposite side and no other joint involvement, an arthrodesis is usually preferred. If he is older and his general condition is satisfactory an arthroplasty may be considered. A limp, fixed deformity or a 
poor range of movement alone are not grounds for arthroplasty, but are to be considered in conjunction with pain, which must always be the principal indication for operation.

Femoral neck fractures, ankylosing spondylitis and congenital dislocation of the hip present special and complicated problems. Their treatment is not discussed in this paper.

\section{FACTORS THAT APPEAR TO HAVE LITTLE INFLUENCE ON THE RESULT OF AN ARTHROPLASTY}

Age-Comparison of the average ages in cases of osteoarthritis in the excellent, good and bad results shows that there is very little difference between the three. Therefore, no patient with osteoarthritis should be denied operation only on account of his age, provided he is otherwise fit (Fig. 1).

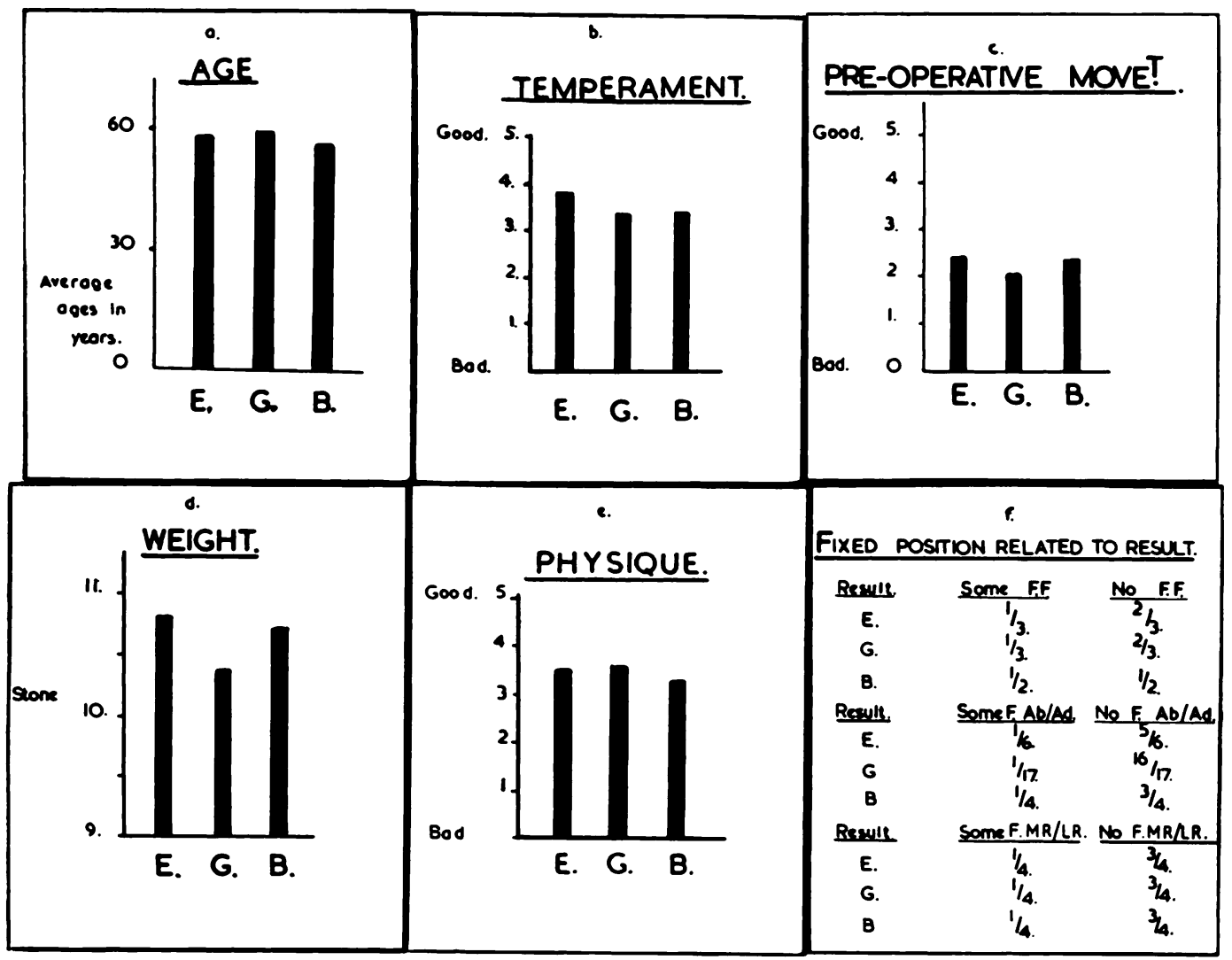

Fig. 1

In these diagrams averages are compared in the excellent (E), good (G) and bad (B) results. These six factors appear to play only a small part in the result of an arthroplasty. Note: In $f, F$.F denotes fixed flexion, F.Ab/Ad denotes fixed abduction or adduction, and F.MR/LR denotes fixed medial or lateral rotation.

Temperament-At the follow-up examination points were given out of a possible five in an attempt to correlate mental make-up with results. The strong, stoical, courageous character was given high marks. The object of this investigation was to find out if it would be fair to advise that an arthroplasty should be done only in patients who were strong in character, with the fortitude necessary to benefit from the early programme of post-operative exercises. Would it be correct to blame the patient's " psyche" for a bad result? Figure 1 shows that the mental make-up of the patients in the excellent, good and bad results was similar; there is little difference between the average figures. It is recognised that assessment is a matter of 
personal judgment rather than scientific measurement, and the difficulty of estimating this factor correctly is obvious. The failure of an arthroplasty is such a major disaster that the value of these figures must be small. Nevertheless, in this series of cases analysis suggests that the patient's mental make-up plays only a small part in the result of an arthroplasty.

Hip movement before operation-Comparison between the three groups of results was made when pre-operative movement had been given points out of a possible five. The results indicate that this is not a factor of great importance. Poor movement before operation may be followed by a good post-operative result, and the converse also applies (Fig. 1).

The patient's weight-No records of the patient's weight before operation were available. Weights were recorded after operation. Despite the fact that a patient who has a bad result would lead a more sedentary life, the difference between the average weights was only 9 per cent. There were many excellent results in patients weighing over 14 stones. Fat patients present technical difficulties at operation, but analysis shows that the result of an arthroplasty has little relation to the patient's weight (Fig. 1).

Physique-The patient's height and weight must be considered in relation to the power of his muscular system. One person who weighs 14 stones may be slim and powerful, whereas another patient of the same weight may be fat and flabby. The estimated strength of a patient in relation to his body weight was assessed out of a possible five. A strong light person would receive five out of five points. Figures show that patients with satisfactory results have only a slightly higher index than those with bad results (Fig. 1).

Fixed deformity after operation-In this series it appears that the result after operation was not related to fixed deformity (Fig. 1).

Conclusion-All these factors do play a part in the result of an arthroplasty, and in summation they may be worth considering, but their part is small when compared with the factors that follow.

\section{FACTORS THAT APPEAR TO BE OF GREAT IMPORTANCE IN THE RESULT OF AN ARTHROPLASTY}

The operation-It is submitted that the operation itself contains all the factors of supreme importance. There are various technical procedures which have to be performed, and there are various manoeuvres which have to be avoided. With these factors correctly observed, and with normal operative skill, success is probable. Without these factors, even superlative pre-operative, operative and post-operative treatment is liable to end in failure.

TABLE II

Result Related to Surgical Approach

\begin{tabular}{|ll|}
\hline \multicolumn{1}{|c|}{$\begin{array}{c}\text { Anterior Smith-Petersen approach } \\
127 \text { cases }\end{array}$} & $\begin{array}{c}\text { Lateral approach with trochanteric osteotomy } \\
46 \text { cases }\end{array}$ \\
\hline 24.4 per cent classified as excellent results & $10 \cdot 8$ per cent classified as excellent results \\
29.5 per cent classified as good results & 23.9 per cent classified as good results \\
4.7 per cent classified as bad results & 26.0 per cent classified as bad results \\
41.4 per cent classified in other intermediate groups & 39.3 per cent classified in other intermediate groups \\
\hline
\end{tabular}

The surgical approach to the hip joint-The anterior Smith-Petersen approach (1939) was used in 60.2 per cent of the cases in this series. The lateral approach with trochanteric osteotomy, upward displacement and subsequent reattachment of the greater trochanter with wire, catgut or screw was used in 21.8 per cent of cases. In the remaining 18 per cent of cases other types of incision had been used. Results in 127 cases performed with the anterior approach are compared with the results in forty-six cases in which the lateral approach with trochanteric osteotomy was used (Table II). Analysis shows that after the anterior Smith-Petersen approach 
the proportion of excellent results was more than twice that after other incisions, and the proportion of bad results less than one-fifth: when the anterior incision was used 53.9 per cent of the cases were classified as presenting excellent or good results, and only 4.7 per cent were classified as presenting bad results. Table III summarises the results from two orthopaedic centres where the anterior Smith-Petersen approach had been used throughout; the results are very similar.

TABLE III

Comparison of Results at Two Centres Using Only the Anterior Smith-Petersen Approach

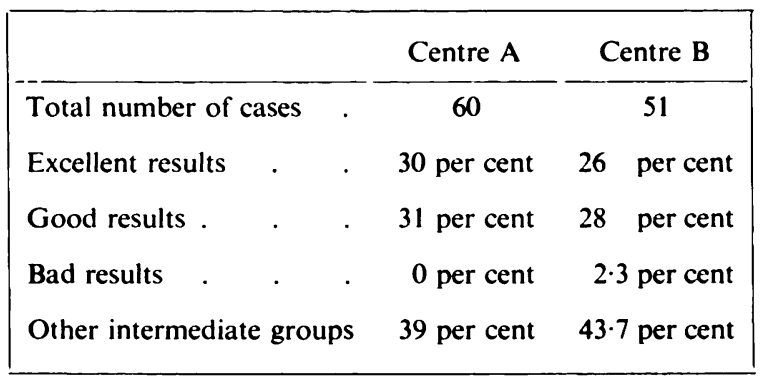

After the lateral approach with trochanteric osteotomy 26 per cent of the patients were dissatisfied with the result, for they still had pain and poor function, and in some instances this was worse than before operation. In approximately three-fifths of these failures a second major operation had to be performed within two years because local injections, radiotherapy, hydrocortisone, physiotherapy or the removal of the wires or screws from the greater trochanter had failed to relieve the pain. Naturally the results two to four years after operation were better than those assessed after one or two years, because by this time only 10 per cent of the unsatisfactory arthroplasties were still arthroplasties. In the other 16 per cent the patients had been subjected to a further operation such as arthrodesis, pseudarthrosis or displacement osteotomy. Hence the apparent improvement in the group. Of the remaining patients operated upon with trochanteric osteotomy $34 \cdot 7$ per cent gained excellent or good results.

It must be stressed that it is the interference with the bone of the greater trochanter that is thought to be one of the principal causes of failure. Arthroplasty through the lateral approach combined with either the muscle-cutting exposure (Gibson 1950) or the muscle-slide exposure (McFarland and Osborne 1954) was followed by good results in the nineteen patients who have been examined. However, a consistent disadvantage of these approaches seemed to be that a positive Trendelenburg's sign persisted longer after this operation than after the Smith-Petersen approach.

The acetabular roof-A good and a poor acetabular roof are illustrated in Figure 2. In all arthroplasties the acetabular roof was measured on the antero-posterior radiograph and these measurements were compared in the cases with excellent, good and bad results. Figure 3 shows that in the cases with excellent results a measurement of over $3 \frac{1}{4}$ centimetres was found almost twice as often as in those with bad results; in the cases with bad results a reading of under $1 \frac{1}{2}$ centimetres was five times as common as in those with excellent results. However, if we go a stage further, comparing the roof measurement in the excellent, good and bad cases after the anterior approach has been used, with similar measurements in the excellent, good and bad results after the lateral approach with trochanteric osteotomy we find that the surgical approach is more important than the roof measurement. Figure 4 shows how rapidly the force per unit area (pressure) rises as the chord length (acetabular roof) diminishes. Figure 5 demonstrates the degree of inward displacement and consequent increase in roof measurement that can and should be achieved. 
The prosthesis or interposition substance-The best results were obtained when a Smith-Petersen Vitallium mould was used. In this series eleven out of eighty-nine Judet prostheses (ten acrylic and one metal) broke. The average time from operation to breakage was under eighteen months. The average period of observation after operation in all cases was twenty-five months. Post-operative complications-If the eleven breakages of the Judet prosthesis are excluded there were few post-operative complications in this series of 211 patients. (Joint pain is not included as a "complication " of arthroplasty; pain means a " failure " of arthroplasty and

\section{ACETABULAR ROOF.}

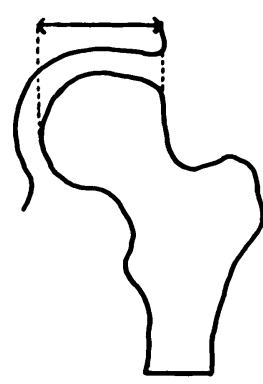

ROOF.

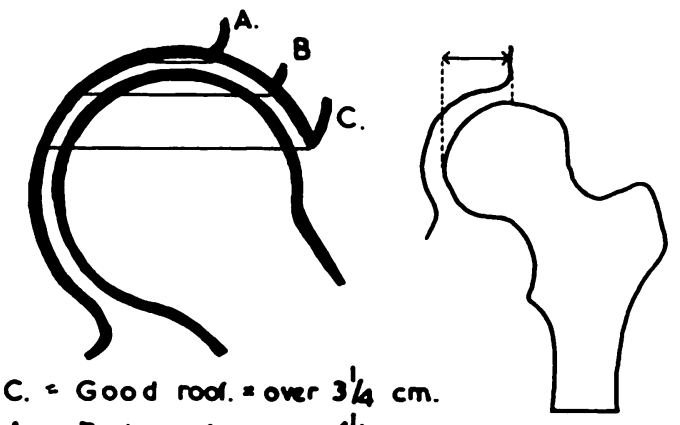

$A$. = Bod rool. = underl'/2 $\mathrm{cm}$. CHORD LENGTHS

POOR ROOF.

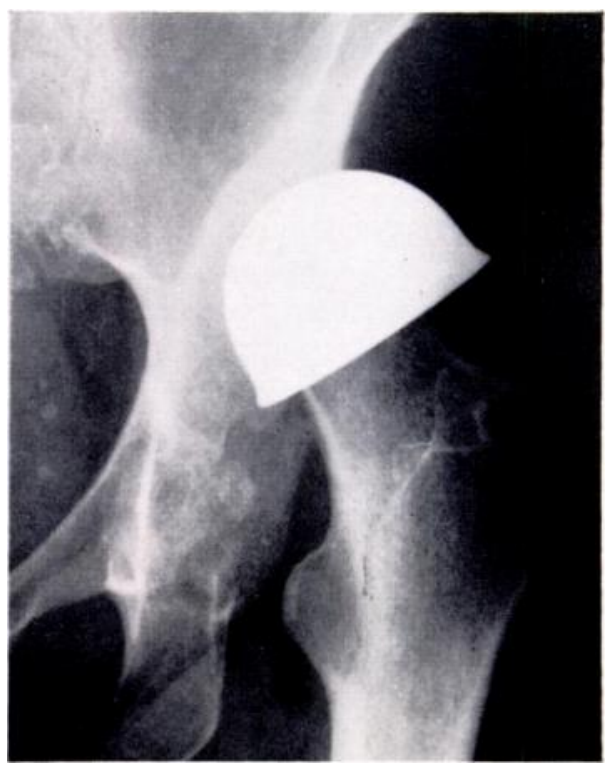

FIG. 2

Diagrams and radiographs illustrating a good and a bad acetabular roof.

is the main factor used in determining the quality of the result.) There were two early deaths from paralytic ileus, one death from haemorrhage from a gastric ulcer in the fourth week. and one from a massive pulmonary embolus in the sixth week; the mortality rate was therefore 1.8 per cent. Two moulds and two Judet prostheses had to be removed because of persistent sepsis. Dislocation of the mould or prosthesis occurred on six occasions; in every case there had been inadequate deepening of the acetabulum. Deep femoral thrombosis with oedema of the leg was observed in six cases. A persistent post-operative foot drop was seen on three 
occasions. A small pulmonary embolus occurred in five patients, minor wound infections seven times, and haematoma of the wound in a total of seven cases. In the early post-operative period there were four times as many complications after the anterior incision as after the

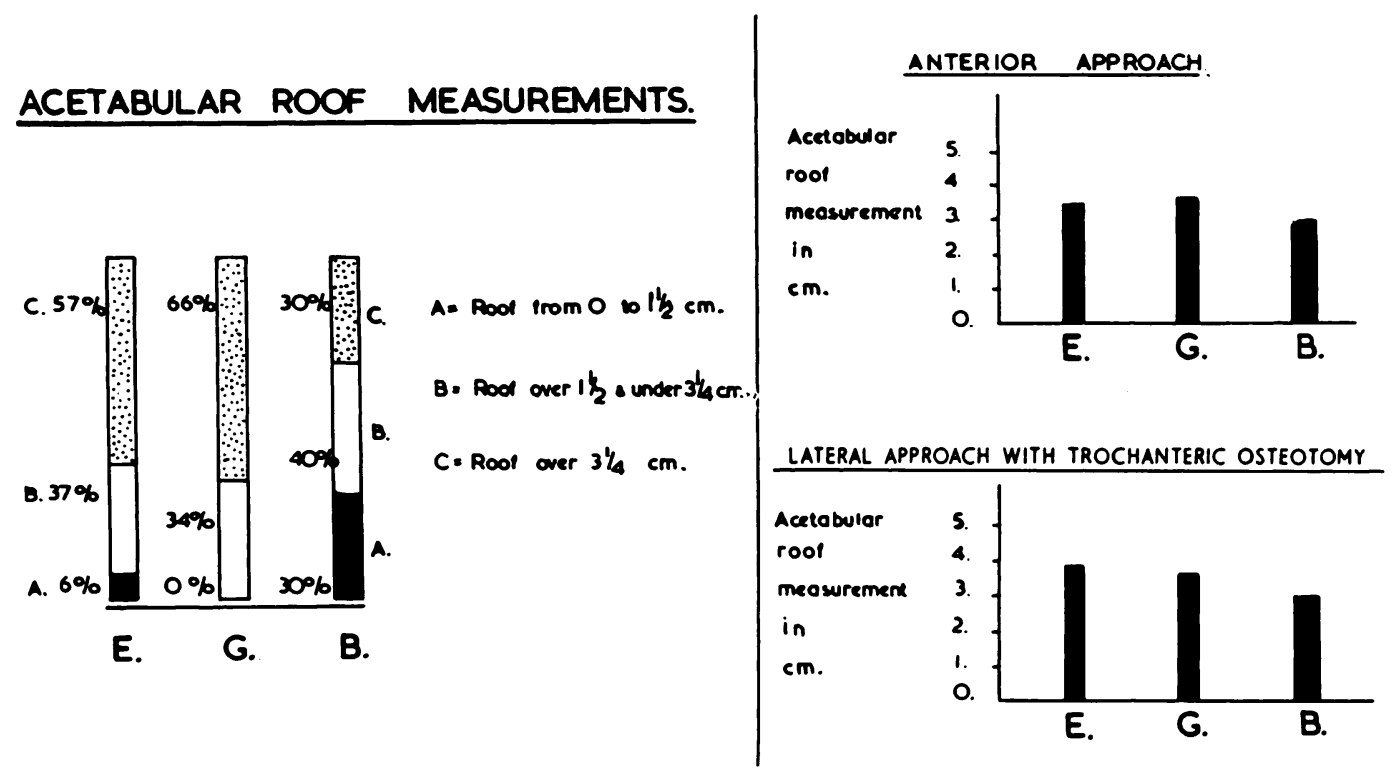

Fig. 3

This diagram illustrates that in the excellent $(E)$ results an acetabular roof measurement of over 31 centimetres occurred almost twice as frequently as in the bad (B) results; in the bad results a reading of under $1 \frac{1}{2}$ centimetres was five times as common as in the excellent results. The relationship of approach to acetabular roof is also illustrated.

lateral. It is possible that many of these complications were due to excessive retraction of the femoral vessels at operation, or to inadequate haemostasis. Thus, unless the anterior approach is correctly done, there are dangers; but the dangers in the early phase are well compensated by the success of this approach in later phases.

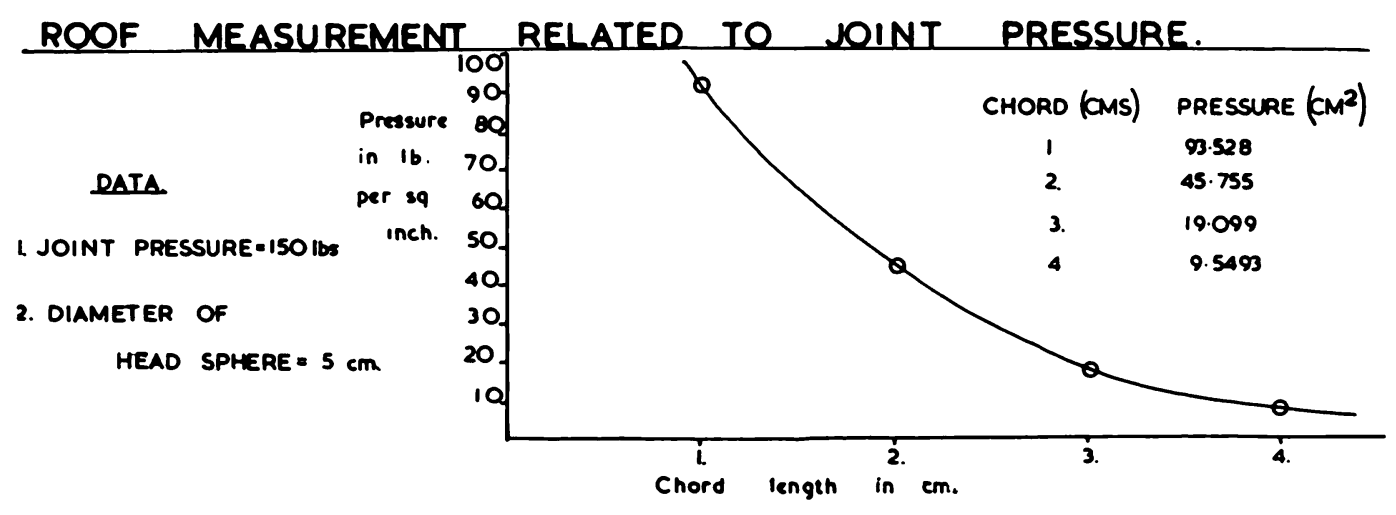

FIG. 4

Diagram to illustrate the relationship between roof measurement and joint pressure.

Late results in a personal series of sixty cases (W. A. L.) - All patients who lived within 100 miles of London and who were operated upon between 1948 and 1949 were asked to attend for follow-up examination. Sixty out of sixty-six patients attended.

VOL. 39 B, NO. 4, NOVEMBER 1957 

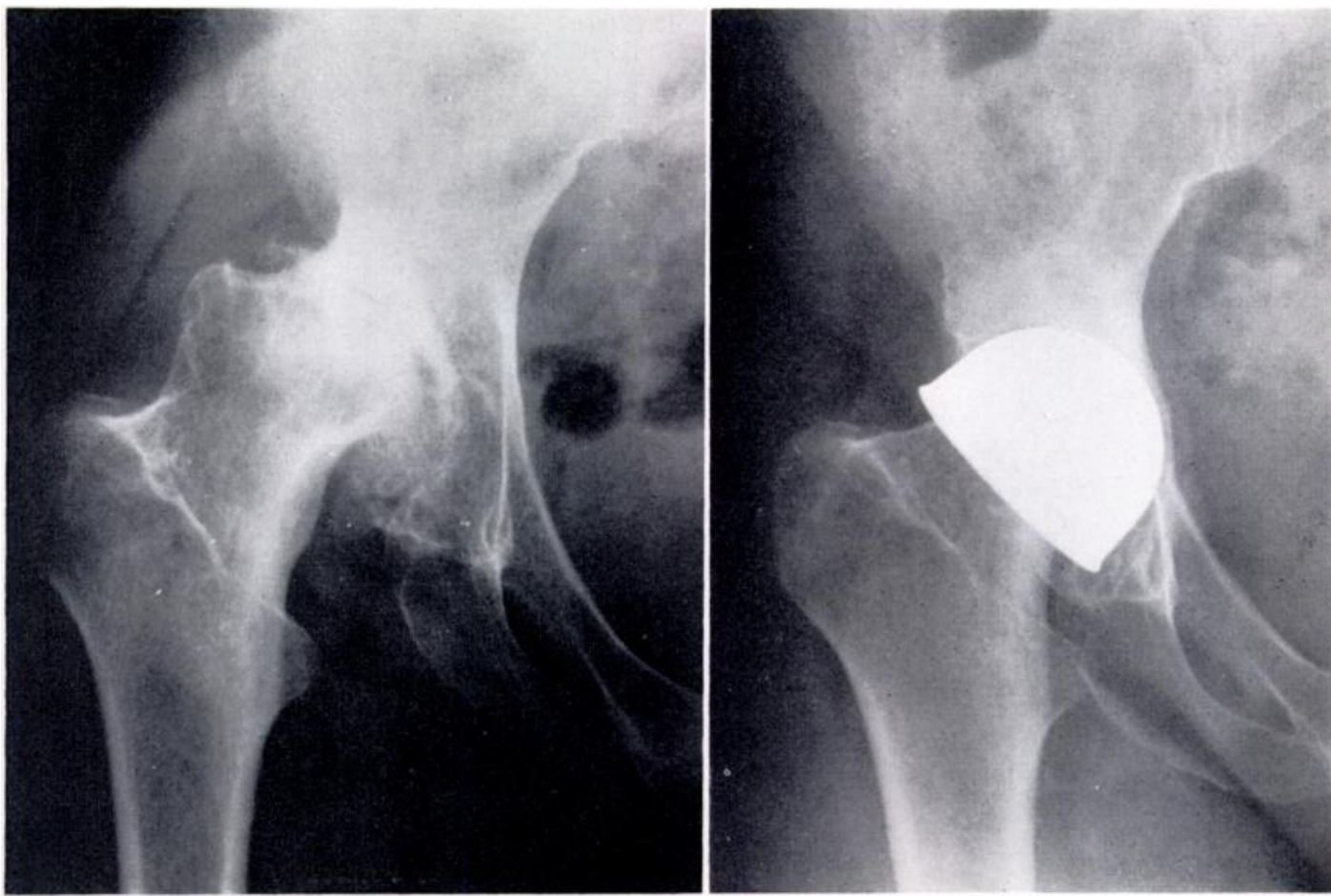

FIG. 5

Radiographs showing the amount of medial displacement and consequent acetabular roof formation that can and should be achieved.

Diagnosis-The reason for the arthroplasty was: osteoarthritis (fifty cases); congenital subluxation of the hip (four cases); ankylosing spondylitis (six cases).

Operation-All arthroplasties followed the pattern described later in this article.

Results-The result was excellent in 30 per cent, good in 31 per cent and fair in 39 per cent. None was classed as bad.

Complications-There was no death and no case of infection. The complications included: haematoma (five); subluxation of the mould (two): small pulmonary embolus (two): and troublesome post-operative shock (two).

\section{SOME POINTS OF IMPORTANCE IN THE OPERATIVE TECHNIQUE}

The technique of the operation has already been described in detail by Smith-Petersen (1948) and by Law (1952), but certain details and slight modifications based on increasing experience of the operation are well worth stressing.

The anterior Smith-Petersen approach reaches the hip joint from above as well as in front. Releasing the iliacus freely on the inner side of the iliac crest allows full and valuable medial retraction of the iliopsoas tendons and muscles. It is not necessary to strip the muscles so freely on the outer side of the iliac crest. In fact, only the region immediately adjacent to the anterior superior spine need be cleared. In this way the important muscles arising from the side of the ilium are left as intact and undisturbed as possible. On a deeper plane the straight and reflected heads of the rectus femoris muscle are divided cleanly by knife dissection, allowing the muscle to be retracted laterally within its sheath. rather than turning it downwards. This is aided materially by dividing the deep fascia over the iliacus muscle as far distally as the motor branch of the femoral nerve. This simple dissection allows a 
surprising degree of relaxation in the whole of the operation area. The capsule is excised from the anterior, superior, inferior and (after dislocation of the joint) posterior surface of the femoral head just proximal to the junction of the head and neck of the femur. A clean-cut capsular margin. rather than rough irregular tags, is less likely to cause bony proliferation in the healing stage, and burning with diathermy also helps in this respect. Like the edge of the capsule, the overgrown bone margins of the acetabular rim and femoral head must also be cut cleanly with a sharp osteotome, and later the raw bone margins are touched with the diathermy. Throughout the operation careful sharp dissection is important; rough subperiosteal stripping predisposes to new bone formation later. The accurate reshaping of femoral head and acetabulum are important points. The acetabulum is reshaped and deepened to the inner pelvic cortex, and a good acetabular roof, doming upwards in the axis of the femoral neck. is essential.

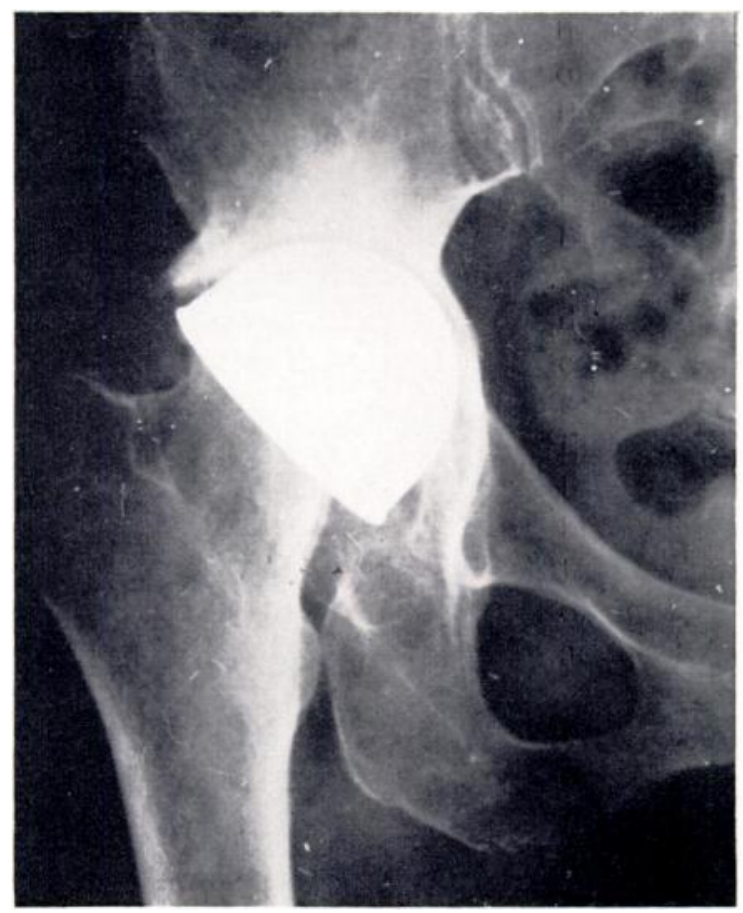

Fig. 6

Radiograph of a cup arthroplasty that satisfies all the criteria discussed. A patient who has such a post-operative radiograph seldom has a bad result.

The use of Vitallium as opposed to ordinary stainless steel is believed to be of significance. No harmful reaction between the metal and the bone has been noted.

In the post-operative management, too much emphasis has been placed on physiotherapy rather than on the patient's own activities. After leaving hospital at the end of seven or eight weeks most patients can carry out their own programme of exercises in conjunction with their ordinary household duties. Only if home or social conditions are inadequate should regular attendance at a physical medicine department be advised. On the other hand. all these patients require regular examination by the surgeon. who should correct faults in gait, decide the time for changing from crutches to sticks and finally for walking unaided, and make any necessary adjustments from alteration in limb length. The avoidance of overfatigue must be stressed. especially in the early stages, and clearly the whole programme must be made elastic and adaptable to the individual patient. who is often elderly. Those in 
sedentary occupations can often return to work in three months, and heavier forms of work are graded accordingly. Clearly, a long and costly rehabilitation is not required when such good use can be made of a patient's own activities such as walking, stair-climbing, bicycling, car driving and the use of public transport.

\section{CONCLUSIONS}

The conclusion to be drawn from the detailed study of this whole series is that arthroplasty can be worth while, particularly in osteoarthritis. Strong preference is given to the SmithPetersen technique, which, however, must be followed meticulously. The early after-care is of great importance, but should not involve a long time in hospital. The emphasis, as in all forms of rehabilitation, should be on the patient's own active exercises and graduated use of the joint.

In the five-year survey of mould arthroplasty, the striking radiological features in the successful results include a sound acetabular roof, the absence of surrounding new bone, the establishment of a new joint space and the maintenance of the original relationship of the mould, femoral head and acetabulum.

The analysis suggests that any Smith-Petersen arthroplasty with no early complications and with a radiograph resembling Figure 6 will be followed by an excellent result in the great majority of cases.

We conclude also that in any series of patients operated upon through the lateral approach with trochanteric osteotomy, it is probable that approximately one patient in four will be dissatisfied with the result, no matter what other factors apply.

\section{SUMMARY}

1. Two hundred and eleven cases of arthroplasty of the hip have been studied in an attempt to establish the causes of success and failure by comparing the excellent, good and bad results. 2. The findings suggest that the result of an arthroplasty depends largely upon four factors: the surgical approach to the hip joint, the acetabular roof, the interposition substance, and the early post-operative complications.

3. Some important points in the technique of operation and in the post-operative management are described.

We are most grateful to Mr A. G. Apley, Mr B. H. Burns, Mr R. J. Furlong, Mr A. Naylor, Professor G. Perkins, Mr F. A. Simmonds and Mr R. H. Young for help and encouragement in the compilation of this review. We are much indebted to Mrs E. Hoare and her staff of the Research and Development Department, Aircraft Division, Messrs Vickers Armstrong Ltd., for their help with the statistics and for supplying Figure 7. We are grateful also to $\mathrm{Mr} \mathrm{W}$. A. Langmead, Physicist to the Radiotherapy Unit at St Thomas's Hospital. One of us was awarded a prize by the South-West Metropolitan Regional Hospital Board for work on which this paper is based. Acknowledgment is made to the Board for permission to publish this work.

\section{REFERENCES}

Gibson, A. (1950): Posterior Exposure of the Hip Joint. Journal of Bone and Joint Surgery, 32-B, 183. LaW, W. A. (1952): Osteoarthritis of the Hip. London: Butterworth \& Co. (Publishers) Ltd.

McFarland, B., and Osborne, G. (1954): Approach to the Hip. A Suggested Improvement on Kocher's Method. Journal of Bone and Joint Surgery, 36-B, 364.

Smith-Petersen, M. N. (1939): Arthroplasty of the Hip. A New Method. Journal of Bone and Joint Surgery, 21, 269.

Smith-Petersen, M. N. (1948): Evolution of Mould Arthroplasty of the Hip Joint. Journal of Bone and Joint Surgery, 30-B, 59.

Smith-Petersen, M. N. (1949): Approach to and Exposure of the Hip Joint for Mold Arthroplasty. Journal of Bone and Joint Surgery, 31-A, 40. 